\title{
Characterization of novel microsatellite markers in Musa acuminata subsp. burmannicoides, var. Calcutta 4
}

\author{
Robert NG Miller*1,2, Marco AN Passos², Natalia NP Menezes², Manoel T Souza Jr33, Marcos M do Carmo Costa4, \\ Vânia C Rennó Azevedo4, Edson P Amorim55, Georgios J Pappas Jr2,4 and Ana Y Ciampi ${ }^{4}$
}

\begin{abstract}
Background: Banana is a nutritionally important crop across tropical and sub-tropical countries in sub-Saharan Africa, Central and South America and Asia. Although cultivars have evolved from diploid, triploid and tetraploid wild Asian species of Musa acuminata (A genome) and Musa balbisiana (B genome), many of today's commercial cultivars are sterile triploids or diploids, with fruit developing via parthenocarpy. As a result of restricted genetic variation, improvement has been limited, resulting in a crop frequently lacking resistance to pests and disease. Considering the importance of molecular tools to facilitate development of disease resistant genotypes, the objectives of this study were to develop polymorphic microsatellite markers from BAC clone sequences for M. acuminata subsp. burmannicoides, var. Calcutta 4. This wild diploid species is used as a donor cultivar in breeding programs as a source of resistance to diverse biotic stresses.
\end{abstract}

Findings: Microsatellite sequences were identified from five Calcutta 4 BAC consensi datasets. Specific primers were designed for 41 loci. Isolated di-nucleotide repeat motifs were the most abundant, followed by tri-nucleotides. From 33 tested loci, 20 displayed polymorphism when screened across 21 diploid M. acuminata accessions, contrasting in resistance to Sigatoka diseases. The number of alleles per SSR locus ranged from two to four, with a total of 56 . Six repeat classes were identified, with di-nucleotides the most abundant. Expected heterozygosity values for polymorphic markers ranged from 0.31 to 0.75 .

Conclusions: This is the first report identifying polymorphic microsatellite markers from M. acuminata subsp. burmannicoides, var. Calcutta 4 across accessions contrasting in resistance to Sigatoka diseases. These BAC-derived polymorphic microsatellite markers are a useful resource for banana, applicable for genetic map development, germplasm characterization, evolutionary studies and marker assisted selection for traits.

\section{Background}

Commercial banana varieties, which are derived from intraspecific crosses within Musa acuminata Colla, together with interspecific hybrid development with Musa balbisiana Colla, are cultivated mostly by smallholder farmers, across over 120 countries in different tropical and sub-tropical environments. As an inexpensive starch source, banana is also rich in fibre, minerals and vitamins. Although an important food commodity in developing countries in terms of production value after

* Correspondence: robertmiller@unb.br

1 Universidade de Brasília, Campus Universitário Darcy Ribeiro, Instituto de Ciências Biológicas, Departamento de Biologia Celular, Asa Norte, Brasília, Brazil Full list of author information is available at the end of the article rice, wheat and maize, genetic improvement has been limited. In wild bananas, sexual recombination results in viable seed. However, the majority of today's commercial cultivars are sterile A and B genome-containing triploids, with seedless fruit development occurring via parthenocarpy, partly as a result of translocations [1]. Conventional breeding in Musa diploids and triploids is also hampered as a result of a low number or complete absence of seeds, caused by either a lack of viable pollen, or inefficient pollinating insects. As many cultivars are evolving asexually via vegetative micropropagation or suckers, their genetic base is narrow, resulting in crops lacking resistance to pests and disease. Given the large 
scale global consumption of susceptible genotypes such as the sterile triploids of the M. acuminata Cavendish cultivar group, global Musa production faces threats by fungal, bacterial and viral pathogens and a number of pests, with greatest disease losses today caused by the fungal pathogens Mycosphaerella fijiensis, causal organism of black Sigatoka disease, and Fusarium oxysporum $\mathrm{f}$. sp. cubense Tropical Race 4, which causes Fusarium wilt. For these reasons, molecular tools for the development of disease resistant genotypes are of paramount importance for the Musa industry.

Highly variable microsatellites or simple sequence repeat loci (SSRs), are abundant, randomly dispersed, locus specific, codominant and multi-allelic markers, which are composed of core repeat sequences of, for example, di- to penta-nucleotides, repeated in tandem. Their application in Musa has included genotyping [2-4], Musa evolution and taxonomy [5], and linkage map saturation [1]. Potential also exists in marker assisted selection (MAS), upon identification of SSRs for gene loci colocalizing with quantitative trait loci (QTLs) for desirable traits. To date, several hundred SSR markers have been developed from M. acuminata and M. balbisiana material [5,2,6-8]. In comparison with other crop species, however, the total number available for genetic analyses remains limited, given that alleles can be absent or monomorphic when applied across cultivars.

We report the development of novel SSR markers from sequenced BAC clones in M. acuminata Calcutta 4. This wild diploid species is resistant to numerous fungal and bacterial pathogens, as well as nematodes. Given its' potential as a source of exploitable genes, this cultivar is widely employed as a donor species in banana breeding programs [9]. Polymorphic loci were identified when tested across 21 potential parental diploid M. acuminata individuals contrasting in resistance to Sigatoka diseases caused by the ascomycete fungi $M$. fijiensis and Mycosphaerella musicola. Such BAC-derived markers are potentially advantageous in that polymorphism can not only be greater than that observed using EST-derived SSRs [10], but subsequent mapping also allows anchoring of individual BAC clones of interest to genetic maps.

\section{Results}

The sequences of five Musa BAC clones were subjected to a computational pipeline targeting perfect SSRs with periodicities ranging from two to ten nucleotides, and an overall length of 12 bases. In total, 41 SSRs were identified comprising six repeat classes. Di-nucleotide repeats are the most abundant $(46.34 \%)$ class, followed by tri$(29.26 \%)$, tetra- $(12.19 \%)$, penta- $(7.31 \%)$, hexa- $(2.43 \%)$ and nona-nucleotide repeats $(2.43 \%)$. The most abundant dinucleotide repeat motifs isolated were AG, AT, CT, and TA $(7.31 \%$ each). By contrast, all tri-nucleotide motifs were equal in abundance (7.31\% each). Generally, the shorter the nucleotide core sequence, the greater were the number of repeats observed, with an average of 12.2 repeats for di-nucleotide motifs, 5.8 for tri, 3.6 for tetra, 3 for penta, 3 for hexa, and 3 for nona-nucleotide motifs. A summary of all designed primer sequences, SSR motifs, theoretical annealing temperature, and expected product size is provided for the 41 loci identified where primers could be designed [Additional file 1]. Twenty out of 33 tested primer pairs reproducibly amplified polymorphic PCR products across the Musa accessions, with allelic patterns under optimized primer conditions given in Table 1. Di-nucleotide repeats were the most abundant polymorphic group, followed by tri, penta and tetranucleotides. From a total of 56 scored alleles, the number of polymorphic alleles ranged from two to four, with an average of 2.8 alleles per locus. Heterozygosity values were calculated using GDA [11] and FSTAT [12], with expected values ranging from 0.31 to 0.75 . Thirteen loci (MABN 09, MABN 12, MABN 14, MABN 16, MABN 18, MABN 21, MABN 24, MABN 31, MABN 33, MABN 37, MABN 38, MABN 39, and MABN 40) were monomorphic in $M$. acuminata accessions. Twelve loci showed departure from Hardy-Weinberg expectations $(\mathrm{P}<0.05$ using Fisher's exact test probability $[\mathrm{P}<0.05]$ based on 2000 shufflings), possibly as a result of sampling, chromosomal inversions or null alleles. Phenomena potentially responsible for null alleles include point mutations and sequence divergence in primer annealing sites, or preferential allele amplification during PCR. In testing for linkage disequilibrium (LD) (FSTAT $\mathrm{P}<0.01$ with Bonferroni correction), no disequilibrium was detected among the loci pairwise combinations. PIC values for allelic diversity ranged from 0.258 to 0.681 .

\section{Discussion}

This is the first report identifying polymorphic microsatellite markers from $M$. acuminata Calcutta 4 across accessions contrasting in resistance to Sigatoka diseases. The availability of these molecular tools will contribute towards development of genetic maps with high marker density, derived from segregant populations for agronomically important traits, and offering potential for downstream application in MAS. Concerted efforts are currently underway by a number of Musa breeding groups for development of segregant mapping populations $[13,14]$.

Also, given difficulties in development of populations in Musa with sufficient numbers of individuals for high resolution mapping, LD mapping has been proposed as an alternative route for identifying genes for traits of interest in Musa [15]. As such an approach requires both hundreds of plant accessions and thousands of markers, the new microsatellite markers characterized in this study 


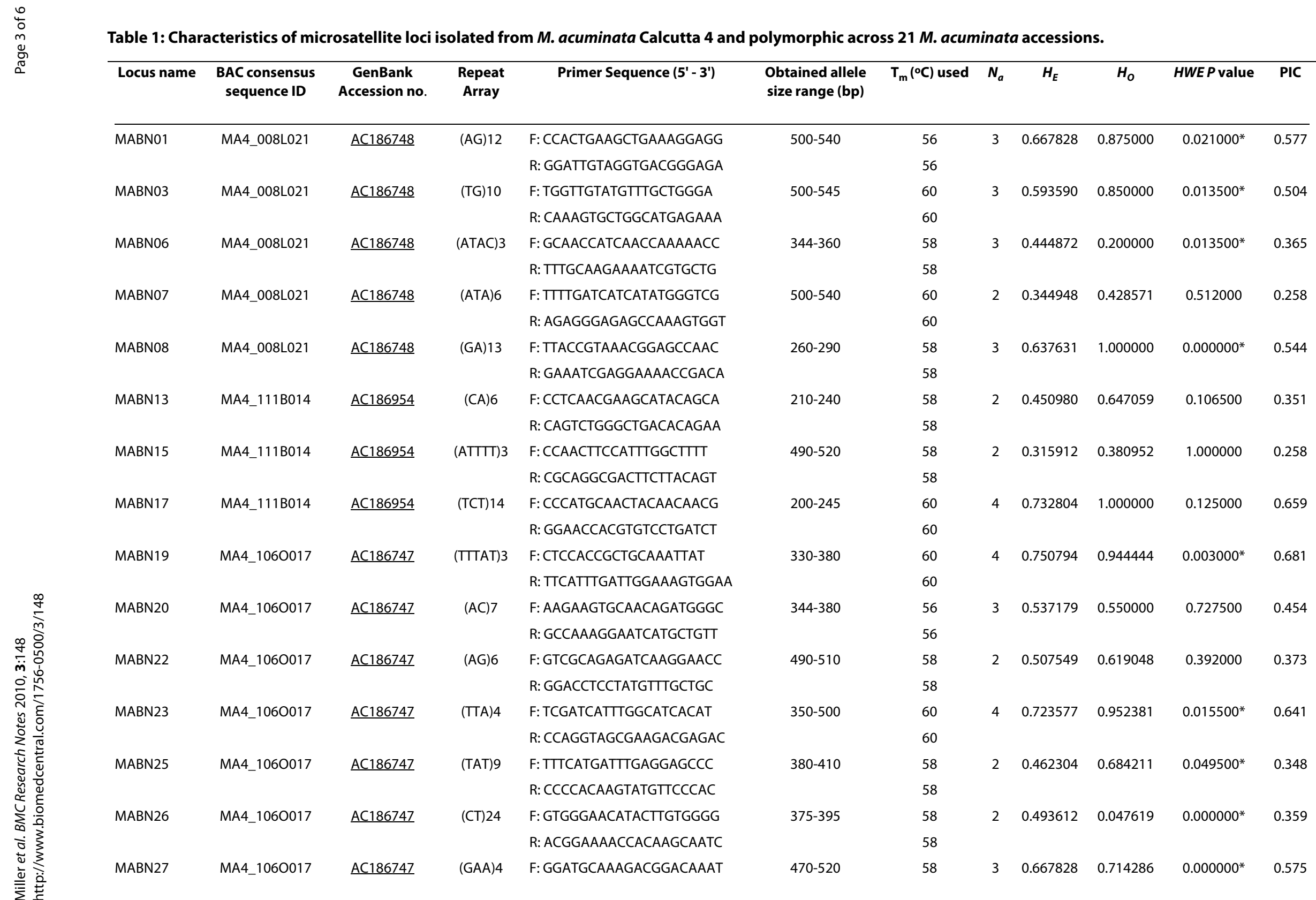


Table 1: Characteristics of microsatellite loci isolated from M. acuminata Calcutta 4 and polymorphic across 21 M. acuminata accessions. (Continued)

\begin{tabular}{|c|c|c|c|c|c|c|c|c|c|c|c|}
\hline & & & & R:TAATGGCTITGCAACTGCTG & & 58 & & & & & \\
\hline \multirow[t]{2}{*}{ MABN28 } & MA4_1060017 & $\underline{\mathrm{AC} 186747}$ & $(\mathrm{GA}) 23$ & F:TGGAGGTCTCAACCAAAACC & $390-410$ & 60 & 2 & 0.480769 & 0.550000 & 0.639500 & 0.367 \\
\hline & & & & R: AGATTGGCTACTGTGGGTGG & & 60 & & & & & \\
\hline \multirow[t]{2}{*}{ MABN29 } & MA4_1060017 & $\underline{\mathrm{AC} 186747}$ & $(\mathrm{GAT}) 5$ & F: ACCAGCCACTGGAATCAAAC & $350-385$ & 60 & 3 & 0.600000 & 0.866667 & 0.069000 & 0.506 \\
\hline & & & & R: GTCTGCTGAAGAGCCAAACC & & 60 & & & & & \\
\hline \multirow[t]{2}{*}{ MABN30 } & MA4_1060017 & AC186747 & (ATTTT)3 & F: CAGCCGTTGATGTTCAAATG & $360-380$ & 60 & 2 & 0.387097 & 1.000000 & $0.000500^{*}$ & 0.321 \\
\hline & & & & R: CGTTACGGTGGATCGTCTIT & & 60 & & & & & \\
\hline \multirow[t]{2}{*}{ MABN34 } & MA4_106O017 & AC186747 & (CT) 18 & F:TAGGTGAGAATGGGACGGAG & $330-355$ & 58 & 3 & 0.661451 & 0.368421 & $0.000000^{*}$ & 0.571 \\
\hline & & & & R: CAGTAGCAGCAACCTGGTGA & & 58 & & & & & \\
\hline \multirow[t]{2}{*}{ MABN35 } & MA4_1060017 & $\underline{\mathrm{AC} 186747}$ & (CT) 14 & F: CTGTCACCAGGTTGCTGCTA & $270-320$ & 56 & 4 & 0.664103 & 0.450000 & $0.005500^{*}$ & 0.569 \\
\hline & & & & R: CTTCCTTGGACCTITCATCG & & 56 & & & & & \\
\hline
\end{tabular}

Tm, annealing temperature used; $\mathrm{Na}$, number of alleles per locus observed; $\mathrm{H}_{\mathrm{E}^{\prime}}$ expected heterozygosity under Hardy-Weinberg expectations; $\mathrm{H}_{\mathrm{O}}$, observed heterozygosity; $\mathrm{H}-\mathrm{W}$, $\mathrm{P}$ value for deviation from Hardy-Weinberg equilibrium, with *significant departure $(\mathrm{P}<0.05)$ from HW equilibrium; PIC, Polymorphism Information Content 
can serve as candidates for such work. Our markers are also a resource for characterizing diversity in wild species, cultivars and landraces deposited in genebanks, and for inferring phylogenetic relationships in Musa.

Finally, considering the increasing availability of genomic resources for $M$. acuminata Calcutta 4, such as BAC libraries [16], EST data sets [17] and candidate disease resistance gene sequences [18], in the context of available next generation sequencing technologies, identification of genes and markers for desirable traits such as resistance to biotic stress will no doubt accelerate considerably in the near future.

\section{Conclusion}

In this study 41 new microsatellite markers were developed for M. acuminata, of which 20 displayed reasonable polymorphism when screened across 21 diploid individuals contrasting in resistance to Sigatoka diseases. Polymorphic markers detected an average of 2.8 alleles per locus, with PIC values ranging from 0.258 to 0.681 . The results also provided some information on repeat class nature and abundance.

\section{Methods}

Data for SSR identification was derived from genomic data (shotgun-sequenced BAC clones from a M. acuminata Calcutta 4 BAC library) [16,19]. A computational search over five BAC consensi datasets [GenBank: $\underline{\mathrm{AC} 186748}, \underline{\mathrm{AC} 186749}, \underline{\mathrm{AC} 186954}, \underline{\mathrm{AC} 186747}$ and AC186750] was performed to locate SSRs with at least two repeating units spanning more than 10 bases, using the program Mreps [20]. Primers flanking microsatellite loci were designed using the program PRIMER3 [21].

From 41 loci identified where primers could be designed, 33 primer pairs were tested for polymorphism. Twenty one diploid (AA) M. acuminata accessions, contrasting in resistance to Sigatoka diseases, and potential parentals for genetic map construction, were used to characterize microsatellite loci. Genomic DNA was extracted from the Black Sigatoka-resistant $M$. acuminata accessions Calcutta 4, Lidi, 0323-03, SH32-63, 130406 and 0116-01; Black Sigatoka-susceptible accessions Pisang Berlin and Niyarma Yik; Yellow Sigatoka-resistant accessions Calcutta 4, Burmanica, Microcarpa, Lidi, 0323-03, 1304-06, 1741-01, 9179-03, 0116-01, 1318-01 and 4279-06; and Yellow Sigatoka-susceptible accessions Raja Uter, Tjau Lagada, F2P2, Khai Nai On, Pisang Berlin, Niyarma Yik, Sowmuk, Jaribuaya and SH32-63. Each PCR reaction was carried out in a $13 \mu$ l volume, containing 3 ng of template genomic DNA, $2.5 \mathrm{mM} \mathrm{MgCl} 2,0.2 \mathrm{mM}$ dNTPs, $0.5 \mu \mathrm{M}$ of each primer, $1.25 \mathrm{U}$ of Taq polymerase, and $1 \times$ PCR buffer (Invitrogen). Amplifications were conducted on a PTC-100 thermocycler (MJ Research), with temperature cycling conducted as follows: initial denaturation at $94^{\circ} \mathrm{C}$ for $5 \mathrm{~min} ; 29$ cycles of $94^{\circ} \mathrm{C}$ for 1 min, specific primer annealing temperature for $1 \mathrm{~min}$, and extension at $72^{\circ} \mathrm{C}$ for $1 \mathrm{~min}$; plus an extra elongation period of $7 \mathrm{~min}$ at $72^{\circ} \mathrm{C}$. Following amplification, PCR products were initially electrophoresed in 3.5\% agarose gels run in $1 \times$ TBE buffer, in order to check amplicon size and PCR specificity. Allele sizes were estimated against 10-bp ladder molecular size standards (Invitrogen) on denaturing $6 \%$ polyacrylamide gels using $7 \mathrm{~m}$ urea, with PCR products visualized by silver staining according to standard protocols. The degree of polymorphism per locus was calculated using GDA software, version 1.2 [11].

\section{Additional material}

Additional file 1 Summary of all designed primer sequences, SSR repeat motif, theoretical annealing temperature ( $\mathrm{Tm})$, and expected product size. A Microsoft Excel table containing a summary of all the designed primer sequences, together with SSR repeat motif, theoretical annealing temperature (Tm), and expected product size

\section{Competing interests}

The authors declare that they have no competing interests.

\section{Authors' contributions}

RNGM participated in the design and implementation of the study, and drafted the manuscript. MANP participated in microsatellite marker validation and data analysis. NNPM participated in microsatellite marker validation. MTSJ conceived the study and participated in implementation of the project. MMCC carried out computational searches for microsatellite identification and designed flanking primers. VCRA participated in data analysis. EPA supervised microsatellite marker validation and editing of the manuscript. GJPJ participated in computational searches for microsatellite identification and primer design, and editing of the manuscript. AYC conceived the study, supervised microsatellite marker validation and data analysis, and commented on the manuscript. All authors read and approved the final manuscript.

\section{Acknowledgements}

This work was funded by the CNPq (Projects 680.398/01-5 and 506165/2004-3), the IAEA (Project 13187), FINEP (Project 0107060900/0842/07), Embrapa and the Universidade Católica de Brasília. MANP was supported by the CNPq.

\section{Author Details}

1 Universidade de Brasília, Campus Universitário Darcy Ribeiro, Instituto de Ciências Biológicas, Departamento de Biologia Celular, Asa Norte, Brasília, Brazil , 2Universidade Católica de Brasília, SGAN 916, Módulo B, Brasília, Brazil, 3EMBRAPA Agroenergia, Parque Estação Biológica - PqEB - Av. W3 Norte, Brasília, Brazil, 4EMBRAPA Recursos Genéticos e Biotecnologia, Parque Estação Biológica - PqEB - Av. W5 Norte, Brasília, Brazil and 5EMBRAPA Mandioca e Fruticultura Tropical, Rua Embrapa, Cruz das Almas, Brazil

Received: 21 December 2009 Accepted: 27 May 2010

Published: 27 May 2010

\section{References}

1. Hippolyte I, Bakry F, Seguin M, Gardes L, Rivallan R, Risterucci AM, Jenny C, Perrier X, Carreel F, Argout X, Piffanelli P, Khan I, Miller RN, Pappas GJ, Mbeguie-A-Mbeguie D, Matsumoto T, De Bernardinis V, Huttner E, Kilian A, Baurens FC, D'hont A, Cote F, Courtois B, Glaszmann JC: A saturated SSR/DArT linkage map of Musa acuminata addressing genome rearrangements among bananas. BMC Plant Biol 2010, 10:65.

2. Crouch JH, Ortiz R, Crouch HK, Ford-Lloyd BV, Howell EC, Newbury HJ, Jarret RL: Utilization of molecular genetic techniques in support of plantain and banana improvement. Acta Hortic 2001, 540:185-191. 
3. Creste S, Tulmann-Neto A, Silva SO, Figueira A: Genetic characterization of banana cultivars (Musa spp.) from Brazil using microsatellite markers. Euphytica 2003, 132:259-268.

4. Amorim EP, Reis RV, Santos-Serejo JA, Amorim VBO, Silva SO: Variabilidade genética estimada entre diplóides de banana por meio de marcadores microssatélites. Pesqui Agropecu Bras 2008, 43:1045-1052

5. Lagoda PJL, Noyer JL, Dambier D, Baurens FC, Grapin A, Lanaud C: Sequence tagged microsatellite site (STMS) markers in the Musaceae. Mol Ecol 1998, 7:657-666.

6. Buhariwalla HK, Jarret RL, Jayashree B, Crouch JH, Ortiz R: Isolation and characterization of microsatellite markers from Musa balbisiana. Mol Ecol Notes 2005, 5:327-330.

7. Creste S, Benatti TR, Orsi MR, Risterucci AM, Figueira A: Isolation and characterization of microsatellite loci from a commercial cultivar of Musa acuminata. Mol Ecol Notes 2006, 6:303-306.

8. Cheung F, Town CD: A BAC end view of the Musa Accuminata genome. BMC Plant Biol 2007, 7:29.

9. Swennen R, Vuylsteke D: Breeding black sigatoka resistant plantains with a wild banana. Trop Agric 1993, 70:74-77.

10. Gao LF: Analysis of microsatellites in major crops assessed by computational and experimental approaches. Molecular Breeding 2003, 12:245-261

11. Lewis PO, Zaykin D: GENETIC DATA ANALYSIS: Computer Program for the Analysis of Allelic Data (version $1.0 \mathrm{~d} 16 \mathrm{c}$ ). [http:// hydrodictyon.eeb.uconn.edu/people/plewis/software.php].

12. Goudet J: FSTAT, a program to estimate and test gene diversities and fixation indices (version 2.9.3.2). [http://www2.unil.ch/popgen/ softwares/fstat.htm]

13. Amorim EP, Lessa LS, da Silva Ledo CA, de Oliveira Amorim VB, Viana dos Reis R, Santos-Serejo JA, de Oliveira e Silva S: Caracterização agronômica e molecular de genótipos diplóides melhorados de bananeira. Rev Bras Frutic 2009, 31:154-161.

14. Lorenzen J, Hearne S, Mbahjo G, Nyine M, Close T: Use of Molecular Markers in Banana and Plantain Improvement. Acta Hortic in press.

15. Heslop-Harrison JS, Schwarzacher T: Domestication, genomics and the future for banana. Ann Bot 2007, 100:1073-1084.

16. Vilarinhos AD, Piffanelli P, Lagoda P, Thibivilliers S, Sabau X, Carreel F, D'Hont A: Construction and characterization of a bacterial artificial chromosome library of banana (Musa acuminata Colla). Theor Appl Genet 2003, 106:1102-1106.

17. Santos CMR, Martins NF, Horberg HM, de Almeida ERP, Coelho MCF, Togawa RC, da Silva FR, Caetano AR, Miller RNG, Souza MT Jr: Analysis of expressed sequence tags from Musa acuminata ssp. burmannicoides, var. Calcutta 4 (AA) leaves submitted to temperature stresses. Theor Appl Genet 2005, 110:1517-1522.

18. Miller RNG, Bertioli DJ, Baurens FC, Santos CMR, Alves PC, Martins NF, Togawa RC, Souza MT Jr, Pappas GJ Jr: Analysis of non-TIR NBS-LRR resistance gene analogs in Musa acuminata Colla: isolation, RFLP marker development, and physical mapping. BMC Plant Biol 2008, 8:15.

19. Lescot M, Piffanelli P, Ciampi AY, Ruiz M, Blanc G, Leebens-Mack J, da Silva FR, Santos CM, D'Hont A, Garsmeur O, Vilarinhos AD, Kanamori H, Matsumoto T, Ronning CM, Cheung F, Haas BJ, Althoff R, Arbogast T, Hine E, Pappas GJ Jr, Sasaki T, Souza MT Jr, Miller RNG, Glaszmann JC, Town CD: Insights into the Musa genome: syntenic relationships to rice and between Musa species. BMC Genomics 2008, 9:58.

20. Kolpakov R, Bana G, Kucherov G: mreps: Efficient and flexible detection of tandem repeats in DNA. Nucleic Acids Res 2003, 31:3672-3678.

21. Rozen S, Skaletsky HJ: PRIMER 3 on the www for general users and for biologist programmers. In Bioinformatics Methods and Protocols: Methods in Molecular Biology Edited by: Krawetz S, Misener S. Totowa, New Jersey, Humana Press; 2000:365-386.

doi: 10.1186/1756-0500-3-148

Cite this article as: Miller et al., Characterization of novel microsatellite markers in Musa acuminata subsp. burmannicoides, var. Calcutta 4 BMC Research Notes 2010, 3:148

\section{Submit your next manuscript to BioMed Centra} and take full advantage of:

- Convenient online submission

- Thorough peer review

- No space constraints or color figure charges

- Immediate publication on acceptance

- Inclusion in PubMed, CAS, Scopus and Google Scholar

- Research which is freely available for redistribution 